\title{
Detection of ultra-weak photon emission in sunflower (Helianthus annuus L.) infested by two spotted-spider mite, Tetranychus urticae Koch-research note
}

\author{
Zsolt Pónya (1) · Ildikó Jócsák (D) \\ Sándor Keszthelyi (D)
}

Received: 10 December 2020 / Accepted: 2 June 2021 / Published online: 6 August 2021

(C) The Author(s) 2021

\begin{abstract}
Sunflower production plays an important role in global industrial oil production. Two-spotted spider mite, Tetranychus urticae, is a dangerous, polyphagous arthropod pest with a cosmopolitan distribution, which can endanger the economic features of global sunflower production. It is widely known that pests trigger various reactions in host plants. Among these, detection of ultra-weak photon emission (UPE) enhanced upon infestation is a novel, non-invasive method suitable for the visualisation and monitoring of both biotic and abiotic stress in living tissues. In the present study, the increase in ultra-weak UPE triggered by biotic stress caused by T. urticae in Helianthus annuus was measured. UPE response of injured plants differed from that of the control plants, which was reflected by a difference in bioluminescence intensity. In leaves attacked by $T$. urticae the onset value of average photon count detected by the sensor and expressed in cps (counts per second) was one order of magnitude higher on average as compared to that revealed by uninjured leaves. Furthermore,
\end{abstract}

Supplementary Information The online version contains supplementary material available at https://doi. org/10.1007/s12600-021-00938-4.

Z. Pónya $\cdot$ I. Jócsák $(\bowtie) \cdot S$. Keszthelyi

Department of Agronomy, Institute of Agronomy,

Hungarian University of Agriculture and Life Sciences,

Kaposvár Campus, Guba Sándor Utca 40, 7400 Kaposvár,

Hungary

e-mail: jocsak.ildiko@uni-mate.hu
UPE emission in infested leaves resulted in an abrupt decrease in the ultra-weak photon emission intensity when assayed as a function of time. The use of this non-invasive imaging technique has allowed the detection of the injury induced by $T$. urticae, as a biotic stressor.

Keywords Biotic stress - Ultra-weak photon emission $\cdot$ Helianthus annuus $\cdot$ Non-destructive imaging $\cdot$ Tetranychus urticae

\section{Introduction}

Ultra-weak photon emission have been widely reported from a wide range of organisms studied hitherto including bacteria (Tessaro et al., 2019), animals used as model systems to investigate pathological states of the human body with the ultimate goal to study the potential of UPE to be integrated into modern medicine (Takeda et al., 2004) and plants (Cifra \& Pospíšil, 2014; Oros \& Alves, 2018; Prasad et al., 2017, 2020a, 2020b; Suzuki et al., 1991) and humans (Tang \& Dai, 2014).

The phenomenon is universally described as the outcome of chemical reactions involving ROS (reactive oxygen species) (Yadav \& Pospíšil, 2012). Although ROS are implicated both in biotic and abiotic stress-induced reactions, in plants they possess key roles in signal transduction pathways in concert with enzymatic and non-enzymatic antioxidant 
systems (Czarnocka \& Karpiński, 2018; Dietz et al., 2016). Stress conditions unleash oxidative burst reported to lead to an elevated level of autoluminescence in living organisms Tsuchida et al. (2019), which is attributed mainly to lipid peroxidation in membranes during the relaxation of the high-energy excited states of intermediates produced as a result of oxidative radical reactions (Cifra \& Pospíšil, 2014). Albeit in case of an unbalanced ROS-antioxidant turnover other macromolecules such as DNA and proteins can be hypothesized to be the cellular targets of ROS, using in vitro oxidation assays Birtic et al. (2011) demonstrated that it is chiefly lipid peroxidation which yields an increase in autoluminescence as in vitro oxidation (followed by imaging) of lipids provided very similar kinetics data as compared to the in vivo dynamics of enhanced autoluminescence concomitantly ensuing upon induced stress in Arabidopsis plants hence supplying indirect evidence that in plants lipid peroxidation is the primary source of UPE. Plants are sessile organismsms which had to evolve mechanisms to counteract against biotic and abiotic stress conditions in situ. One of the major biotic stress conditions jeopardising crop production worldwide is the damage caused by pests.

Two-spotted spider mite Tetranychus urticae Koch, 1836 (Arachnida: Acari: Tetranychidae) is a cosmopolitan herbivore, which was described to occur in the European fauna (Bolland et al., 1998). It is a polyphagous pest, possessing piercing-sucking mouthparts, by which it feeds through penetrating photosynthetic tissues of plant leaves. Information regarding Helianthus annuus being the host of the Tetranychidae family (Navvab-Gojrati \& Zare, 1978) is scarce. Its presence is revealed by spin-fine strands of webbing, which can be usually seen in the apex of sprouts and leaves. Its nymphs and adults reside primarily on the underside of the host plant leaf. Small chlorotic and necrotic spots appear on the attacked leaf due to its injected saliva and to mechanical damage caused by sucking to the cells. Even total defoliation may occur if the infestation brought about by mites is not controlled (Nyoike \& Liburd, 2013).

It is widely known that pests trigger various reactions in host plants. These plant responses are comparable to hypersensitive reactions in plant tissues caused by phytopathogen microorganisms (Klement \& Goodman, 1967) or secondary metabolites produced by plants
(Bennett \& Wallsgrove, 1994) upon damage caused by herbivores.

A novel approach based on a relatively unexplored method in the field of plant pest science is bioluminescence imaging of stressed plants. In plant sciences, studies employing non-destructive image techniques have remained relatively scarce (Staedler et al., 2013). Consequently, the potential of bioluminescence imaging in plant protection research remains to be exploited. It is only recently that this non-invasive approach is starting to gain attention in insect research (Usui et al., 2019). The measurement permits the non-invasive and label-free detection of oxidative states in cells (Cifra \& Pospísili, 2014) leaf wound in Spathiphyllum (Oros \& Alves, 2018) and in Arabidopsis (Prasad et al., 2017; 2020). Furthermore, UPE has been used on plants detecting factors inducing plant disorders, such as heat stress (Kobayashi et al., 2014), flood (Kamal \& Komatsu, 2016) high fertigation (Oszlányi et al., 2020). Therefore, UPE imaging may prove to be a valuable means in precision agriculture to address issues related to plant disease control and stress adaptation of crops.

The purpose of this study was to determine, whether biotic stress unleashed by a piercing-sucking arthropod pest, T. urticae, is possible to be detected in $H$. annuus using advanced ultra-weak photon imaging technology.

\section{Materials and methods}

Plant growth conditions and artificial infestation

Helianthus annuus L. seeds were surface sterilised in 3\% sodium hypochlorite for $3 \mathrm{~min}$, prior to thoroughly rinsing and soaking them for $6 \mathrm{~h}$ in distilled water. Seeds were transferred into commercially available potting soil and placed into a growth chamber (Pol-Eco Apartura KK 1450, Poland) under set conditions of $20^{\circ} \mathrm{C} ; 120 \mu \mathrm{M} \mathrm{m}^{-2} \mathrm{~s}^{-1}$ light intensity, 12-12 h light/dark period, 50-70\% relative humidity (RH) and 380 ppm $\mathrm{CO}_{2}$ concentration. The H. annuus plants were raised in 5-5 repetitions. Plants were grown in a climate chamber until they reached the 4-5 leaf-stage.

Artificial infestation occurred at the 4-5 leaf-stages of examined plants by placing $T$. urticae specimens on the leaves ( 5 adults per leaf). The experimental 
arthropods originated from a sunflower acreage area near Kaposvár (Somogy county, Hungary. Following artificial infestation, the infested plants were placed back into the climate chamber, where optimal abiotic conditions $\left(27 \mathrm{C}^{\circ}\right.$ and $\left.60 \%-85 \% \mathrm{RH}\right)$ for $T$. urticae were set up (Shih et al., 1976). The spider mites were allowed to feed on the plants for $72 \mathrm{~h}$ before measurements were taken. The individuals of the control plant population were grown in a separate growth chamber programmed for abiotic conditions identical with those in the infestation chamber.

\section{UPE measurement}

Shoots and leaves of 4-5 leaf stage of Helianthus annuus grown under controlled conditions were used to measure UPE. Both intact and infested shoots/ leaves of approximately the same size were placed into the NightShade LB 985 Plant Imaging Instrument (Berthold Technologies, Bad Wildbad, Germany). Luminescence emissions deriving from the test plants were imaged using a highly sensitive, thermoelectrically-cooled $\left(-74{ }^{\circ} \mathrm{C}\right) \mathrm{CCD}$ camera (NightOWLcam, Berthold Technologies, Germany) mounted onto a dark, light-tight chamber. The samples were dark-adapted for 10 min prior to the measurements in order to ensure that the signals detected by the solid state CCD sensor of the camera represent only UPE-signals and are not attributable to delayed fluorescence (DF)-derived photon emission due to electron-recoupling of the photosynthetic system. According to Gould et al. (2009), who employed a set-up very similar to the one used in this study, concluded that luminescence decayed rapidly reaching an undetectable level (within $50 \mathrm{~s}$ ), therefore a 10-min delay was considered to be sufficient to avoid DF-derived signals impinging on the camera chip. Additionally, to avoid "masking" of UPE-signals by potentially arising DF-derived increase in pixel intensity values, an "IR cut-off" (BG-38 filter cutting of light waves over the $660 \mathrm{~nm}$ bandwidth) filter mounted onto a computer-controlled filter wheel was employed in front of the camera lens hence eliminating potentially arising, "unwanted" signals deriving from delayed fluorescence attributable to chlorophyll molecules in excited state. For image analysis, the IndiGo software ${ }^{\mathrm{TM}}$ (Software Version 2.0.5.0., Berthold Technologies, Germany) was used. A back-lit, midband-coated full frame chip with a spectral range of 350-1050 nm (quantum efficiency: $90 \%$ at $620 \mathrm{~nm}$ ) was employed for photon detection and XY-imaging. In order to increase detection sensitivity, the variable binning was set to: $2 \times 2$ resulting in final resolution of $512 \times 512$ pixels and $26 \times 26 \mu^{2}$ pixel size (slow scan mode). The exposure time was set to: $60 \mathrm{~s}$. The "dark counts" (measured when applying the same parameters without the samples placed inside the imaging chamber) were subtracted from the pixel intensity values prior to analysis. The pixel intensities were rendered into mathematical values (cps, counts per second) used for off-line analysis of the acquired pixel intensity values via the IndiGo ${ }^{\mathrm{TM}}$ software in an Excel-compatible form.

Statistical analysis

The effect of damage caused by T. urticae on UPE and on its temporal dynamics infested sunflower leaves were statistically analysed by two-way ANOVA. Mean values were separated by using the Tukey (HSD) test, at $\mathrm{P} \leq 0.05$. Furthermore, the dynamics of UPE emissions of healthy versus injured leaves as a function of time were examined by correlationregression analysis. SPSS for Windows 11.5 software package was used for both statistic evaluations.

\section{Results}

Figure 1A shows the background level of cps (counts per second). The UPE emission of infested plants differed from that of intact ones (Fig. 1B and C), which was reflected by the difference in bioluminescence intensity as revealed by the cps-analysis based on using the algorithm of the IndiGo software ${ }^{\mathrm{TM}}$ (Berthold Technologies, Germany) which permitted the rendering of pixel intensities into mathematical values. The UPE response presented in Fig. 1C shows how the presence of $T$. urticae-caused damage is visualised by the means of a highly sensitive CCD-camera on both the adaxial and abaxial sides of the leaves during a five-minute imaging period. Healthy plants showed a low level UPE, as the visualised values represented by a pseudo-colour bar (on the right sides of the images) were in the range of 11-30 cps on average, as opposed to the infested leaves, where the bulk 


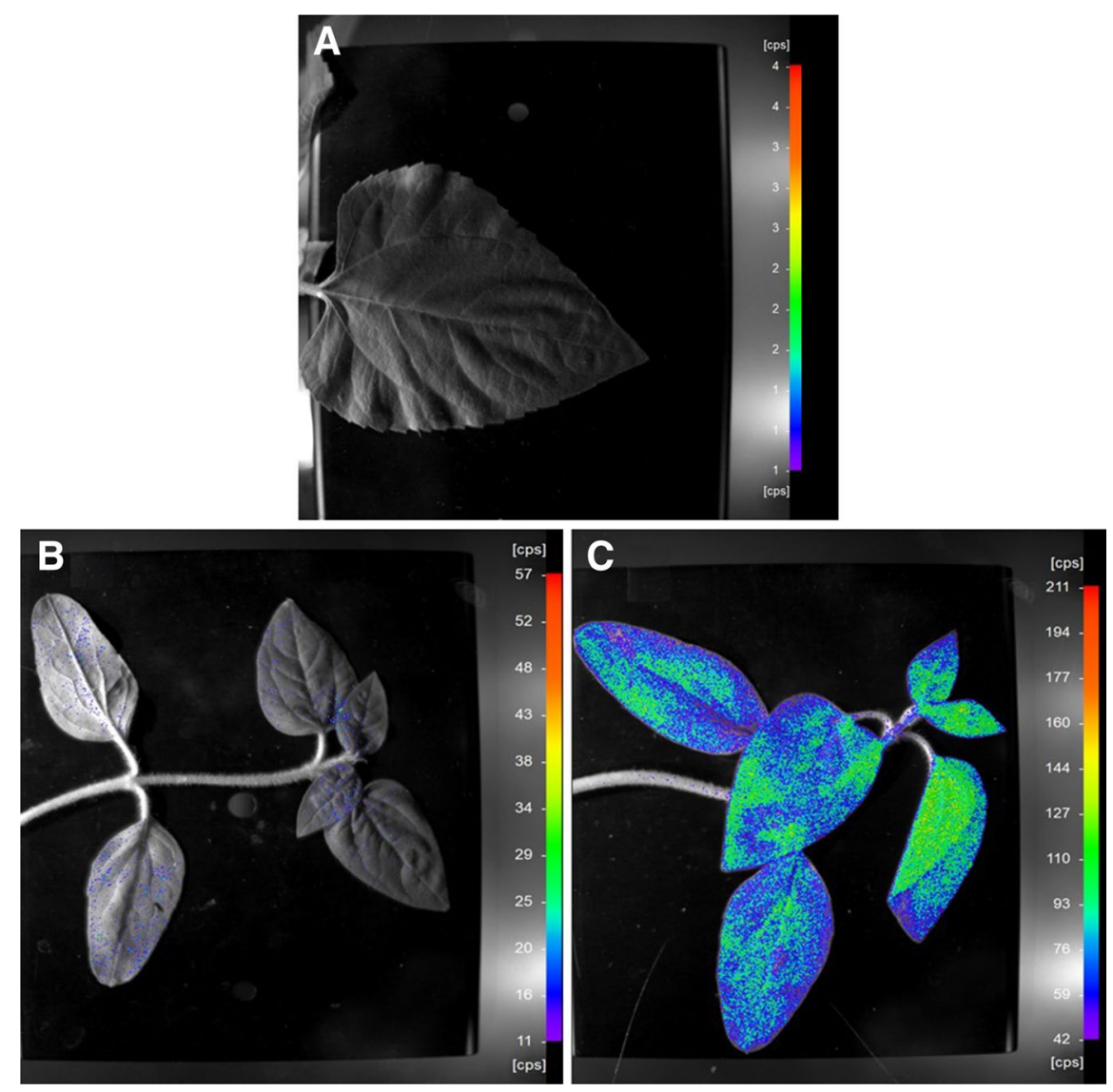

Fig. 12 D-overlay images of black and white photos and the corresponding pseudo colours-coded pixel intensity values representing the spatial distribution and intensity of UPE (ultraweak photon emission). (A) shows the grey-scale image of UPE 5 min following dark-adaptation on a plant leaf put in the lighttight dark chamber, The overlay image of the pseudo-colours coded image and the black-and white photo of an intact shoot $12 \mathrm{~h}$ prior to infestation (B) and that of a shoot of an infested

of pixels belonged to the $42-120 \mathrm{cps}$ range, albeit in few pixels the cps value rose up to the 150-177 range (Fig. 1). As opposed to healthy plants, the abaxial side of leaves of the infested plants (Fig. 1B) showed a more intense UPE than those arising from the adaxial side of the leaves thereby reflecting the infestation habit of T. urtica (as it feeds mainly on the abaxial side of the plant that it attacks)

Furthermore, the infestation habit of T. urticae was "visually" revealed, since the abaxial side of the leaf in Fig. 1B showed a more intense UPE (110-127 cps), than those arising from the adaxial side of the leaves. This is further corroborated by the observation that the UPE signals did not differ on the different sides
Helianthus annuus plant (C). The intensity colour bars on the right side of the images show signal intensities of pixels detected by the CCD-sensor and converted into colour- codes via the analysis software, according to the scale established through the manufacturer's calibration procedure ensuring traceability to a standard certified by PTB (Braunschweig, Germany)

of leaves of healthy plants. The Kolmogorov-Smirnof normality test showed that the bioluminescence data obtained are of a normal distribution, $P^{>} 0.05$. The effect of $T$. urticae damage on the UPE of sunflower leaves $(P=0.0043)$, as well as the dynamics of the signal decay show time dependence $(P=0.0002)$ as it was statistically confirmed by two-way ANOVA. Besides, the impact of these two independent factors on UPE emission also showed a significant relationship $(P=0.0003)$.

The time-dependent feature of the UPE signals is shown in Fig. 2B-C. First, the background light emission was measured to ensure that the signals detected by the sensor were not 'contaminated' by 

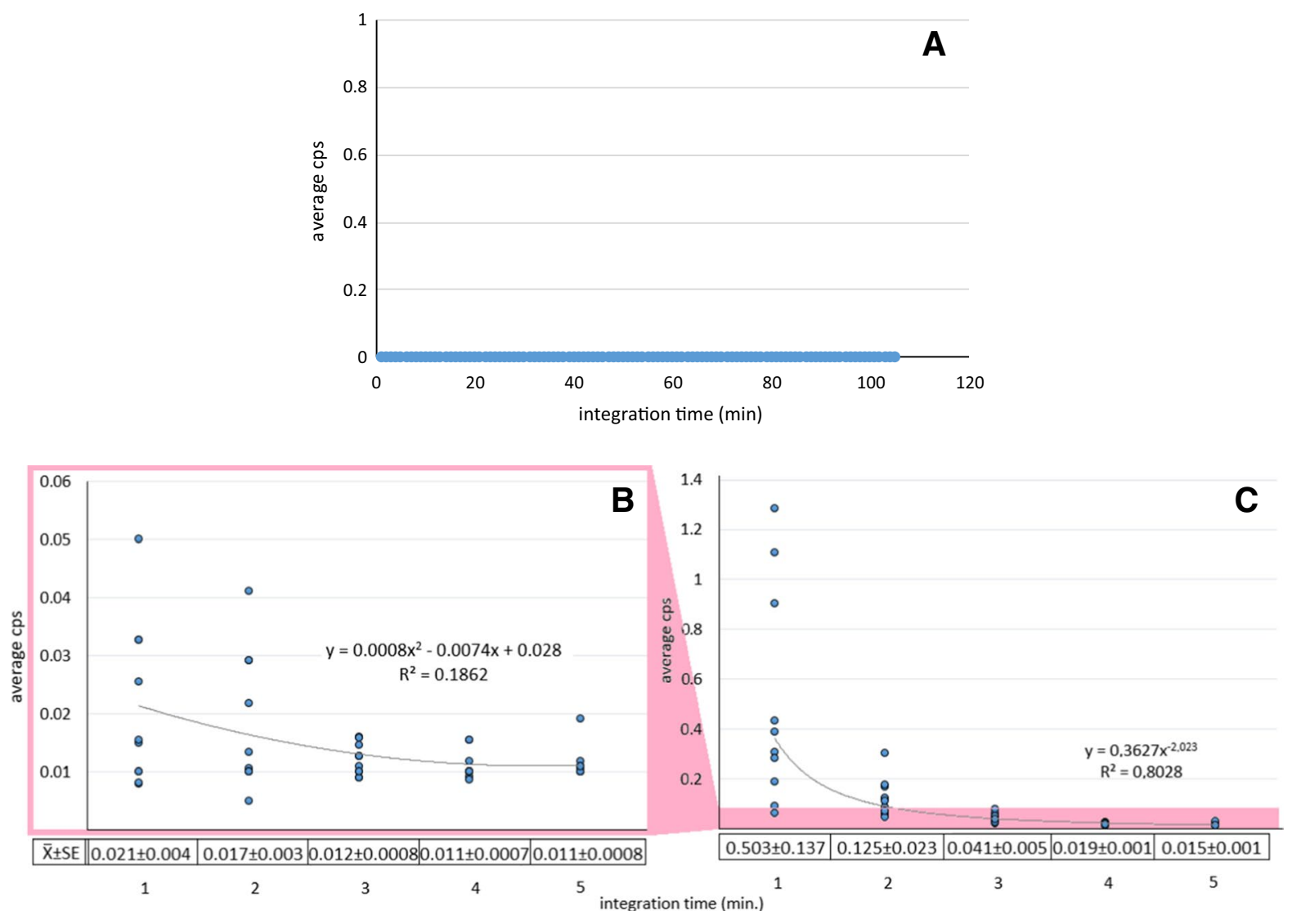

Fig. 2 Data of UPE emission (average counts per second) recorded from leaves of Helianthus annuus leaves and processed according to the Tukey (HSD) test $(P<0.05)$ : A the background level of photon emission was measured with camera-settings identical with those employed during the imaging

the dark current of the camera and/or photon emission in the dark chamber (Fig. 2A). The changing of average cps as a function of time showed a powertype tendency in both the intact and damaged samples. The correlations between these two examined factors were rather close, which were confirmed by the registered $\mathrm{R}$ squares. The maximum average cps values fell in the range of $0.01-0.05$ in healthy plants, whereas 0.01-1.4 in infested leaves, which indicates a two orders of magnitude difference (Fig. 2B-C). Furthermore, the average cps values showed a decrease as a function of time, during the five-minute imaging period. This decreasing tendency (although at a different rate) appeared in both the healthy and infested leaves. of the plant samples B: control (untreated), C: infested with $T$. urticae. Spots represent standard deviation of the mean among five biological replicates. The pink-coloured part of the figure indicates the order of magnitude differences between the control and infested samples

In leaves attacked by $T$. urticae a higher onset value of average cps as compared to that revealed by uninjured leaves resulted in a relatively abrupt decrease in the ultra-weak photon emission intensity when assayed as a function of time.

\section{Discussion}

According to our results, the UPE signals visualised by the highly-sensitive CCD camera, reveal a considerable difference between the healthy and $T$. urticae infested leaves of $H$. annuus as in the uninjured plant individuals the highest detected UPE signal was lower, than the lowest detected signal of infested 
leaves on both sides of the leaves. Moreover, although both DF and UPE emission measurements can be used to monitor the stress status of plants (Hennecke \& Brüx, 2012), there is a remarkable difference between their signal intensity in stressed vs. intact plants; the latter being substantially enhanced in stressed plants as compared to spontaneous, low-level bioluminescence (typical of healthy plants), while in the stressed state the former (DF) being much lower (as compared to the healthy state). Thus, the finding that the signal intensity of luminescence in the infested plants was two orders of magnitude higher as compared to that in healthy plants suggests that the detected signals are indeed attributable to UPE triggered by stress brought about by infestation.

T. urticae feed mainly on the abaxial surface of the leaves, which was clearly seen from the UPE signals, since the abaxidal side of the leaf was bright green that indicates a more intensive signal, as compared to the adaxial sides of leaf, where the signal was between the blue and the green range, indicating lower UPE intensity. The reason for this phenomenon may be that although the mite mainly feeds on the abaxial side of the leaf, the symptoms caused by T. urticae can be seen on both sides, as a result of the translaminar feature of the salivary. Furthermore, not only the intensities of the detected signals were significantly higher in the infested individuals, than in the healthy plants, but also the number of pixels identified (by the software) as sources of signals increased. This defence response is probably due to the accumulation of secondary metabolites triggered upon infestation that impacts on the stress signalling network via effects of enhanced ROS production and cellular redox metabolism. ROS are mostly produced in plants in chloroplasts, mitochondria, and plasma membranes (Baxter et al., 2014; Woodson, 2016), and play a central role in signalling mechanisms in plants especially during plant responses to environmental stimuli and stress agents. When the rate of the generation of these highly reactive molecules exceeds that of their elimination by enzymatic and non-enzymatic antioxidants, they can damage biomolecules (nucleic acids, proteins, lipids) (Ahmad et al., 2008). In this context it is worth mentioning that several studies have been performed to monitor the rate of oxidative damage caused by ROS following feeding by T. urtica (Kusnierczyk et al.,
2008). Leitner et al. (2005) observed elevated ROS formation, also. Liang et al. (2017) confirmed the increase in the levels of peroxidase (POD) and polyphenol oxidase (PPO) both on the enzymatic and gene expression level. Santamaria et al., (2018, 2020) reported that silencing of genes playing part in ROS degradation resulted in higher leaf damage compared to wild-type plants, which clearly indicates ROS production as a consequence of spider mite attack, as is also implied in thus study.

Another issue that was highlighted by the results of five-minute imaging period is the time-dependent and statistically significantly different decrease of the signal at the set sensitivity of the sensor in both healthy and infested leaves. This finding points to an increasing need for a deeper and more detailed investigation of the kinetics of UPE signals in crops. In order to elucidate this issue, a longer imaging period will be paralleled to the measurement of the extent of ROS production by traditional methods, such as superoxide dismutase assay, being the first enzyme of the antioxidative enzyme system, the activity of which is altered by enchanced ROS production.

In summary, based on our findings, it can be concluded that the imaging of the spatio-temporal dynamics of UPE appears to be suitable for the assessment of stress induced by $T$. urticae on $H$. annuus. In light of our results, the extent to which the UPE imaging-based approach capitalised on in the current study could assist in monitoring the stages of two spotted-spider mite infestations with special regard to the particular life strategy and reproduction mode of this agronomically important pest. For instance, the venue potentially leading to the possibility of correlating (the range of) cps-values with the degree of infestation is worth exploring. All these information suggest a putatively successful future application of UPE measurement, as its non-invasiveness and stress-detecting capability correspond to the criteria of integrated pest management and sustainable plant protection. Importantly, the application of highly-sensitive CCDtechnology allowing for spatio-temporal analysis of ultra-low photon emissions may contribute to the enhancement of our understanding as to the intricate relationship between the function of living systems and light. 
Acknowledgements The work was supported by the EFOP-3.6.3.VEKOP-16-2017-00008 and the EFOP-3.6.3-VEKOP-16-2017-00005 projects. The project is co-financed by the European Union, the European Social Fund

Authors' contributions Sándor Keszthelyi designed the study. Zsolt Pónya and Sándor Keszthelyi collected the samples. Zsolt Pónya performed the experiments. Sándor Keszthelyi statistically analysed the data. Zsolt Pónya Ildikó Jócsák and Sándor Keszthelyi wrote the manuscript. All authors read and approved the final manuscript.

Funding Open access funding provided by Hungarian University of Agriculture and Life Sciences. The work was supported by the EFOP-3.6.3.-VEKOP-16-2017-00008 and the EFOP-3.6.3-VEKOP-16-2017-00005 projects. The project is co-financed by the European Union, the European Social Fund.

Data availability Not applicable.

Code availability Not applicable.

\section{Declarations}

Ethics approval Not applicable.

\section{Consent to participate Not applicable.}

\section{Consent for publication Not applicable.}

Conflict of interest There is no conflict of interest.

Open Access This article is licensed under a Creative Commons Attribution 4.0 International License, which permits use, sharing, adaptation, distribution and reproduction in any medium or format, as long as you give appropriate credit to the original author(s) and the source, provide a link to the Creative Commons licence, and indicate if changes were made. The images or other third party material in this article are included in the article's Creative Commons licence, unless indicated otherwise in a credit line to the material. If material is not included in the article's Creative Commons licence and your intended use is not permitted by statutory regulation or exceeds the permitted use, you will need to obtain permission directly from the copyright holder. To view a copy of this licence, visit http://creativecommons.org/licenses/by/4.0/.

\section{References}

Ahmad, P., Sarwat, M., \& Sharma, S. (2008). Reactive oxygen species, antioxidants and signaling in plants. Journal of Plant Biology, 51, 167-173. https://doi.org/10.1007/ BF0303069

Baxter, A., Mittler, R., \& Suzuki, N. (2014). ROS as key players in plant stress signalling. Journal of Experimental Botany, 65, 1229-1240. https://doi.org/10.1093/jxb/ert375
Bennett, R. N., \& Wallsgrove, R. M. (1994). Secondary metabolites in plant defence mechanisms. New Phytologist, 127(4), 617-633. https://doi.org/10.1111/j.1469-8137. 1994.tb02968.x

Birtic, S., Ksas, B., Genty, B., Mueller, M. J., Triantaphylidès, C., \& Havaux, M. (2011). Using spontaneous photon emission to image lipid oxidation patterns in plant tissues. The Plant Journal, 67, 1103-1115. https://doi.org/10. 1111/j.1365-313X.2011.04646.X

Bolland, H. R., Gutierrez. J., \& Flechtmann, C. H. W. (1998). World catalogue of the spider mite family (Acari: Tetranychidae). Brill.

Cifra, M., \& Pospíšil, P. (2014). Ultra-weak photon emission from biological samples: Defnition, mechanisms, properties, detection and applications. Journal of Photochemistry and Photobiology B Biology, 139, 2-10. https://doi. org/10.1016/j.jphotobiol.2014.02.009

Czarnocka, W., \& Karpiński, S. (2018). Friend or foe? Reactive oxygen species production, scavenging and signaling in plant response to environmental stresses. Free Radical Biology \& Medicine, 122, 4-20. https://doi.org/10.1016/j. freeradbiomed.2018.01.011

Dietz, K. J., Mittler, R., \& Noctor, G. (2016). Recent progress in understanding the role of reactive oxygen species in plant cell signaling. Plant Physiology, 171, 1535-1539. https://doi.org/10.1104/pp.16.00938

Gould, P. D., Diaz, P., Hogben, C., Kusakina, J., Salem, R., Hartwell, J., \& Hall, A. (2009). Delayed fluorescence as a universal tool for the measurement of circadian rhythms in higher plants. The Plant Journal, 58, 893-901. https://doi. org/10.1111/j.1365-313X.2009.03819.x

Hennecke, M., \& Brux, A. (2012). Measurement of biophoton emission in plants-an alternative monitoring system for stress factors. Berthold Technologies, AN985 005v1

Kamal, A. H. M., \& Komatsu, S. (2016). Proteins involved in biophoton emission and flooding-stress responses in soybean under light and dark conditions. Molecular Biology Reports, 43, 73. https://doi.org/10.1007/ s11033-015-3940-4

Klement, Z., \& Goodman, R. N. (1967). The hypersensitive reaction to infection by bacterial plant pathogens. Annual Review of Phytopathology, 5, 17-44. https://doi.org/10. 1146/annurev.py.05.090167.000313

Kobayashi, K., Okabe, H., Kawano, S., Hidaka, Y., \& Hara, K. (2014). Biophoton emission induced by heat shock. PLoS ONE, 9(8), e105700. https://doi.org/10.1371/journal.pone. 0105700

Kusnierczyk, A., Winge, P., Jørstad, T. S., Troczynska, J., Rossiter, J. T., \& Bones, A. M. (2008). Towards global understanding of plant defence against aphids - timing and dynamics of early Arabidopsis defence responses to cabbage aphid (Brevicoryne brassicae) attack. Plant, Cell \& Environment, 31, 1097-1115. https://doi.org/10.1111/j. 1365-3040.2008.01823.x

Leitner, M., Boland, W., \& Mithöfer, A. (2005). Direct and indirect defences induced by piercing-sucking and chewing herbivores in Medicago trunculata. New Phytologist, 167, 597-606. https://doi.org/10.1111/j.1469-8137.2005. 01426.x

Liang, X., Chen, Q., Lu, H., et al. (2017). Increased activities of peroxidase and polyphenol oxidase enhance 
cassava resistance to Tetranychus urticae. Experimental and Applied Acarology, 71, 195-209. https://doi.org/10. 1007/s10493-017-0125-y

Navvab-Gojrati, H. A., \& Zare, N. (1978). Resistance of different varieties of sunflower and safflower to Tetranychus turkestani Ugarov and Nikolski in southern Iran. Indian Journal of Entomology, 40(3), 299-302.

Nyoike, T. W., \& Liburd, O. E. (2013). Effect of Tetranychus urticae (Acari: Tetranychidae), on marketable yields of field-grown strawberries in north-central Florida. Journal of Economic Entomology, 106, 1757-1766. https://doi. org/10.1603/EC12033

Oszlányi, R., Mirmazloum, I., Pónya, Z., Szegő, A., Jamal, S., Bat-Erdene, O., \& Papp, I. (2020). Oxidative stress level and dehydrin gene expression pattern differentiate two contrasting cucumber F1 hybrids under high fertigation treatment. International Journal of Biological Macromolecules, 161, 864-874. https://doi.org/10.1016/j.ijbiomac. 2020.06.050

Oros, C. L., \& Alves, F. (2018). Leaf wound induced ultraweak photon emission is suppressed under anoxic stress: Observations of Spathiphyllum under aerobic and anaerobic conditions using novel in vivo methodology. PLOS ONE, 13(6), e0198962. https://doi.org/10.1371/journal.pone. 0198962

Prasad, A., Sedlářová, M., Kale, R. S., et al. (2017). Lipoxygenase in singlet oxygen generation as a response to wounding: In vivo imaging in Arabidopsis thaliana. Scientific Reports, 7, 9831. https://doi.org/10.1038/ s41598-017-09758-1

Prasad, A., Gouripeddi, P., Devireddy, H. R. N., Ovsii, A., Rachakonda, D. P., Wijk, R. V., \& Pospíšil, P. (2020a). Spectral distribution of ultra-weak photon emission as a response to wounding in plants: An in vivo study. Biology, 9(6), 139. https://doi.org/10.3390/biology9060139

Prasad, A., Sedlářová, M., Balukova, A., Rác, M., \& Pospíšil, P. (2020b). Reactive oxygen species as a response to wounding: In vivo imaging in arabidopsis thaliana. Frontiers in Plant Science, 10, 1660. https://doi.org/10.3389/ fpls.2019.01660

Santamaria, M. E., Arnaiz, A., Velasco-Arroyo, B., Grbic, V., Diaz, I., \& Martinez, M. (2018). Arabidopsis response to the spider mite Tetranychus urticae depends on the regulation of reactive oxygen species homeostasis. Scientific Reports, 8, 9432.

Santamaria, M. E., Arnaiz, A., Rosa-Diaz, I., GonzálezMelendi, P., Romero-Hernandez, G., Ojeda-Martinez, D. A., Garcia, A., Contreras, E., Martinez, M., \& Diaz, I. (2020). Plant defenses against tetranychus urticae: mind the gaps. Plants, 9, 464. https://doi.org/10.3390/plant s9040464
Shih, C. T., Poe, S. L., \& Cromroy, H. L. (1976). Biology, life table and intrinsic rate of increase of Tetranychus urticae. Annals of the Entomological Society of America, 69, 362-364.

Staedler, Y. M., Masson, D., \& Schönenberger, J. (2013). Plant tissues in $3 \mathrm{~d}$ via $\mathrm{X}$-ray tomography: Simple contrasting methods allow high resolution imaging. PLoS ONE, 8(e75295), 1-9. https://doi.org/10.1371/journal.pone. 0075295

Suzuki, S., Usa, M., Nagoshi, T., Kobayashi, M., Watanabe, N., Watanabe, H., \& Inaba, H. (1991). Two-dimensional imaging and counting of ultraweak emission patterns from injured plant seedlings. Journal of Photochemistry and Photobiology B., 9, 211-217.

Takeda, M., Kobayashi, M., Takayama, M., Suzuki, S., Ishida, T., Ohnuki, K., Moriya, T., \& Ohuchi, N. (2004). Biophoton detection as a novel technique for cancer imaging. Cancer Science., 95, 656-661.

Tang, R., \& Dai, J. (2014). Biophoton signal transmission and processing in the brain. Journal of Photochemistry and Photobiology b., 2014(139), 71-75. https://doi.org/10. 1016/j.jphotobiol.2013.12.008

Tessaro, L. W. E., Dotta, B. T., \& Persinger, M. A. (2019). Bacterial biophotons as non-local information carriers: Species-specific spectral characteristics of a stress response. Microbiology Open, 8(6), e00761. https://doi.org/10.1002/ mbo3.761

Tsuchida, K., Iwasa, T., \& Kobayashi, M. (2019). Imaging of ultraweak photon emission for evaluating the oxidative stress of human skin. Journal of Photochemistry and Photobiology b, Biology, 198, 111562.

Usui, S., Tada, M., \& Kobayashi, M. (2019). Non-invasive visualization of physiological changes of insects during metamorphosis based on biophoton emission imaging. Scientific Reports, 9, 8576. https://doi.org/10.1038/ s41598-019-45007-3

Woodson, J. D. (2016). Chloroplast quality control-balancing energy production and stress. New Phytologist, 212, 36-41. https://doi.org/10.1111/nph.14134

Yadav, D. K., \& Pospíšil, P. (2012). Evidence on the formation of singlet oxygen in the donor side photoinhibition of photosystem II: EPR Spin-trapping study. PLoS ONE, 7(9), e45883. https://doi.org/10.1371/journal.pone.0045883

Publisher's note Springer Nature remains neutral with regard to jurisdictional claims in published maps and institutional affiliations. 